\title{
DISTINGUISHING KNOWLEDGE FROM INFORMATION A Prerequisite for Elaborating KM Initiative Strategy
}

\author{
Michel Grundstein \\ MG Conseil, 4 rue Anquetil, 94130 Nogent sur Marne, France \\ Paris Dauphine University, Place du Maréchal De Lattre de Tassigny 75775 Paris, France \\ mgrundstein@mgconseil.fr
}

Position paper. The First Conference on Knowledge Management and Information Sharing. Madeira, Portugal, 6-8 october 2009, KMIS (http://www.kmis.ic3k.org/). Completed, and Revisited version $01 / 02 / 2011$

\begin{abstract}
Keywords: Information, Knowledge, Knowledge Management (KM), Individual's tacit knowledge, Commensurability of Individual's Interpretative Frameworks, , General KM initiative development, Strategic KM Orientations Phase, Enterprise's Information and Knowledge System (EIKS), Data, Information, Tacit and Explicit Knowledge Process (DITEK Process).

Abstract: Although the technological approach of Knowledge Management (KM) is greatly shared, without awareness, when elaborating KM initiative's strategy, we can confuse the notions of information and knowledge, and disregard the importance of individual's tacit knowledge used in action. Therefore, to avoid misunderstanding during the strategic orientation phase of a general $\mathrm{KM}$ initiative development, it is fundamental to clearly distinguish the notion of information from the notion of knowledge. Consequently, we propose an empirical model enabling to distinguish the notions of information and knowledge so called DITEK. This model shows the role of individual's interpretative frameworks and tacit knowledge, establishing a discontinuity between information and knowledge. In this paper, we argue that Knowledge cannot be considered as an object such as data are in digital information systems. This pragmatic vision needs thinking about the architecture of an Enterprise's Information and Knowledge System (EIKS), which must be a basis of discussion during the strategic orientation phase of a general KM initiative. Further, we insist on the importance to integrate the individual as a component of the EIKS).
\end{abstract}

\section{INTRODUCTION}

Very often, Knowledge Management (KM) is considered from a technological viewpoint. Thus, as observed by Kjaergaard, Kautz and Nielsen (2008) "The practice of knowledge management is often reduced to the implementation of new IT-based systems, procedures for documenting and sharing information, and documents themselves though there are examples to the contrary. By focusing on externalisation and documentation of knowledge, important organizational aspects, in particular human and social issues, can be over looked (p. 71)." That practice induces to consider knowledge as an object independent of individuals. In that way, as information, knowledge can be acquired, processed, stocked, transmitted and restored. However, we argue that as soon as knowledge is explicit, formalized and codified in a Digital Information System (DIS), it becomes information. We call that information "information source of knowledge for somebody." Effectively, individual's tacit knowledge is involved to enable the user to give a sense to that information in order to act. As noticed by Wiig (2008) "Without knowledge, intelligent and effective behaviour - the ability to interpret, assess, understand, innovate, decide, act, and monitor - will not be possible even if the best information is made available (p.2)." However, if information can be acquired, processed, stored, transmitted and restored, such is not the case for individual's tacit knowledge used in action.

Although the technological approach is greatly shared, without awareness, when elaborating KM 
initiative's strategy, we can confuse the notions of information and knowledge, and disregard the importance of individual's tacit knowledge used in action. Therefore, to avoid misunderstanding during the strategic orientation phase of a Knowledge Management initiative, it is fundamental to clearly distinguish the notion of information from the notion of knowledge. Further, we insist on the importance to integrate the individual as a component of the Enterprise's Information and Knowledge System (EIKS).

In this paper, after having put down background theory and assumptions, we propose a model enabling to distinguish the notions of information and knowledge so called DITEK process model. This model shows the role of individual's interpretative frameworks and tacit knowledge, establishing a discontinuity between information and knowledge. This pragmatic vision needs thinking about the architecture of an Enterprise's Information and Knowledge System (EIKS), which must be a basis of discussion during the KM initiative's strategic orientations phase.

\section{BACKGROUND THEORY AND ASSUMPTIONS}

\subsection{Creation of Individual's Tacit Knowledge}

Our approach is built upon the assumption emphasized by Tsuchiya (1993) concerning knowledge creation ability. He states, "Although terms 'datum', 'information', and 'knowledge' are often used interchangeably, there exists a clear distinction among them. When datum is sense-given through interpretative framework, it becomes information, and when information is sense-read through interpretative framework, it becomes knowledge (p.88)". Figure 1 represents our own interpretation of Tsuchiya's assumption.

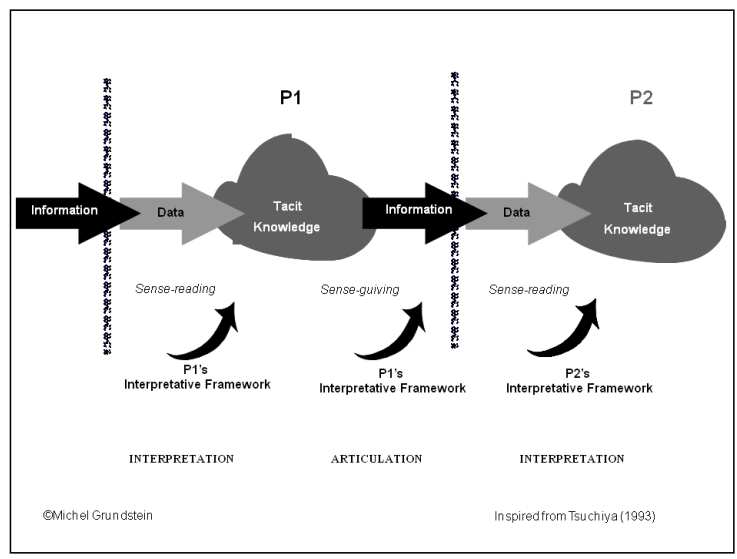

Figure 1: Creation of individual's tacit knowledge

In other words, we can say that tacit knowledge that resides in our brain results from the sense given, through our interpretative frameworks, to data that we perceive among the information transmitted to us. Or rather, Knowledge exists in the interaction between an Interpretative Framework (incorporated within the head of an individual, or embedded into an artefact), and data.

In a different way, Wiig (2004) who highlights a discontinuity between information and knowledge describes this process clearly. He states, "The process, by which we develop new knowledge, uses prior knowledge to make sense of the new information and, once accepted for inclusion, internalizes the new insights by linking with prior knowledge. Hence, the new knowledge is as much a function of prior knowledge as it is of received inputs. A discontinuity is thus created between the received information inputs and the resulting new knowledge (p. 73)."

Consequently, we postulate that knowledge is not an object processed independently of the person who has to act. So, we can say that formalized and codified knowledge, that are independent from individual, are not more than information. Furthermore, as emphasized by Haeckel (2000) we must discern "the knowledge of knower and the codification of that knowledge (p. 295)."

\subsection{Definition of Knowledge Management (KM)}

In 1990, the Initiative for Managing Knowledge Assets (IMKA, 1990) was initiated by a few companies (Carnegie Group, Inc., Digital Equipment Corporation, Ford Motor Company, Texas Instruments, Inc., and US WEST Advanced Technologies, Inc.). They defined for the first time the notion of knowledge assets: "Knowledge assets 
are those assets that are primary in the minds of company's employees. They include design experience, engineering skills, financial analysis skills, and competitive knowledge."

Gradually, numerous research works were carried out, enterprise's KM initiatives were deployed, and an abundant literature enriched the domain of Knowledge Management. So that the concept of KM highlighted a broad range of topics and became a fuzzy concept taking as many senses as people speaking about it. For instance, in his editorial preface, untitled "What is Knowledge Management?" Jennex (2005) has gathered some authors' definitions that show that there is no common evidence about what KM is. Regan (2007) consolidates this observation. She states, "This lack of agreement on a definition of knowledge management seems atypical for an emerging discipline that traces its roots back at least two decades. Even the most recent textbooks in the field spend an entire chapter just explaining what knowledge management is and what it is not, and provide an entire page of definitions."

The introduction to KMIS 2009 conference shows the same understanding: "There are several perspectives on KM, but all share the same core components, namely: People, Processes and Technology. Some take a techno-centric focus, in order to enhance knowledge integration and creation; some take an organizational focus, in order to optimize organization design and workflows; some take an ecological focus, where the important aspects are related to people interaction, knowledge and environmental factors as a complex adaptive system similar to a natural ecosystem."

We can add that most of time, KM is considered from a technological viewpoint. For example, let's consider the European Project Team in charge to elaborate The European Guide to Good Practice in Knowledge Management on behalf of the European Committee for Standardization Workshop on Knowledge Management. This Workshop was running from September 2002 till September 2003. The Project Team has collected, categorized and analyzed more than $140 \mathrm{KM}$ Frameworks. It may be noted that this work has produced a high-quality practical outcome that can be used as a reference point to achieve a good understanding of KM (CEN1, 2004). Nevertheless, as contributors to this project, we observed that few of them were "peoplefocused" as highlighted by Wiig (2004). We can underline the predominant positivist paradigm and the technological approach of KM that have inspired the project team. As a result, the authors consider a system of interrelated objects that can be described independently of individual. That has induced them to consider the knowledge as an object, and so to disregard the importance of people.

Furthermore we distinguished two main approaches underlying KM: (i) a technological approach that answers a demand of solutions based on the technologies of information and communication (ICT); and (ii) a managerial and sociological approach that integrates knowledge as resources contributing to the implementation of the strategic vision of the company. On the one hand, the technological approach leads to reduce knowledge to codified knowledge that is no more than information. In that case KM initiatives can be managed in the same way than Information System projects. On the other hand, the managerial and sociological approach that integrates knowledge as a resource is centered on the core business processes, and people.

In our research group, relying on Tsuchiya's works (Tsuchiya, 1993) we argue that knowledge is dependent of the individual's interpretative framework, and the context of his action. Consequently, knowledge resides primarily in the heads of individuals, and in the social interactions of these individuals. It cannot be consider as an object such as data are in digital information systems. Thus, it appears that KM addresses activities, which utilize and create knowledge more than knowledge by itself. With regard to this question, since 2001, our group of research has adopted the following definition of KM (Grundstein and RosenthalSabroux, 2003): "KM is the management of the activities and the processes that enhance the utilization and the creation of knowledge within an organization, according to two strongly interlinked goals, and their underlying economic and strategic dimensions, organizational dimensions, sociocultural dimensions, and technological dimensions: (i) a patrimony goal, and (ii) a sustainable innovation goal (p.980)." The patrimony goal has to do with the preservation of knowledge, their reuse and their actualization; it is a static goal. The sustainable innovation goal is more dynamic. It is concerned with organizational learning that is creation and integration of knowledge at the organizational level. 


\section{DISTINGUISHING THE NOTIONS OF INFORMATION AND KNOWLEDGE}

Numerous authors analyzed the notions of data, information and knowledge. Let us quote notably Davenport and Prusak (1998, pp.1-6)), Sena and Shani (1999), Takeuchi, and Nonaka, (2000), Amin, and Cohendet, (2004, pp. 17-30), Laudon and Laudon, (2006, p. 416). Besides, Snowden (2000,) makes the following synthesis: "The developing practice of knowledge management has seen two different approaches to definition; one arises from information management and sees knowledge as some higher-level order of information, often expressed as a triangle progressing from data, through information and knowledge, to the apex of wisdom. Knowledge here is seen as a thing or entity that can be managed and distributed through advanced use of technology...The second approach sees the problem from a sociological basis. These definitions see knowledge as a human capability to act (pp. 241-242)." Here, one must think "Wisdom" as the level of the "collective, application of knowledge in action" (Sena 1999, p.8-4), or as "the collective and individual experience of applying knowledge to the solution of problems (Laudon and Laudon 2006, p. 416)." In the following paragraphs, we clarify our approach.

\subsection{Commensurability of Interpretative Frameworks and Individual Sense-Making}

Tsuchiya emphases how organizational knowledge is created through dialogue, and highlighted how "commensurability" of the interpretative frameworks of the organization's members is indispensable for an organization to create organizational knowledge for decision and action. Here, commensurability is the common space of the set of interpretative frameworks of each member (e.g. cognitive models or mental models directly forged by education, experience, beliefs, and value systems). Tsuchiya states "It is important to clearly distinguish between sharing information and sharing knowledge. Information becomes knowledge only when it is sense-read through the interpretative framework of the receiver. Any information inconsistent with his interpretative framework is not perceived in most cases. Therefore, commensurability of interpretative frameworks of members is indispensable for individual knowledge to be shared (p. 89)."

Therefore, we consider information as knowledge when members having a large commensurability of their set of interpretative frameworks commonly understand it. In that case, we call it "information source of knowledge for someone." Such is the case for members having the same technical or scientific education, or members having the same business culture. In these cases, formalized and codified knowledge make the same sense for each member. However, one must take into account that interpretative frameworks evolve in a dynamic way: they are not rigid mindsets. Especially, when considering that, as time is going on, contexts and situations evolve. Thus, the contribution of scientific results, techniques and new methods, the influence of young generations being born with Web (Y generation or Digital Native), the impact of identity crisis and multiple cultures, modify the interpretative frameworks, and create a gap between individuals' commensurability of interpretative frameworks.

\subsection{From Data to Information, and Tacit and Explicit Knowledge: the DITEK Process Model}

Let's consider two individuals $\mathrm{P}_{1}$ and $\mathrm{P}_{2}$ acting in different contexts and situations, at different points in time (Fig. 2). While $\mathrm{P}_{1}$ 's previous knowledge is necessary for elaborating information from data gathered and filtered in the present time, once created this information becomes a frozen object. This static object is independent from $\mathrm{P}_{1}$, and time. Then, at another time, when this information is captured by $\mathrm{P}_{2}$, only some data contained in the information are selected and interpreted, taking sense for $\mathrm{P}_{2}$. In that way, the $\mathrm{P}_{2}$ 's tacit knowledge is modified.

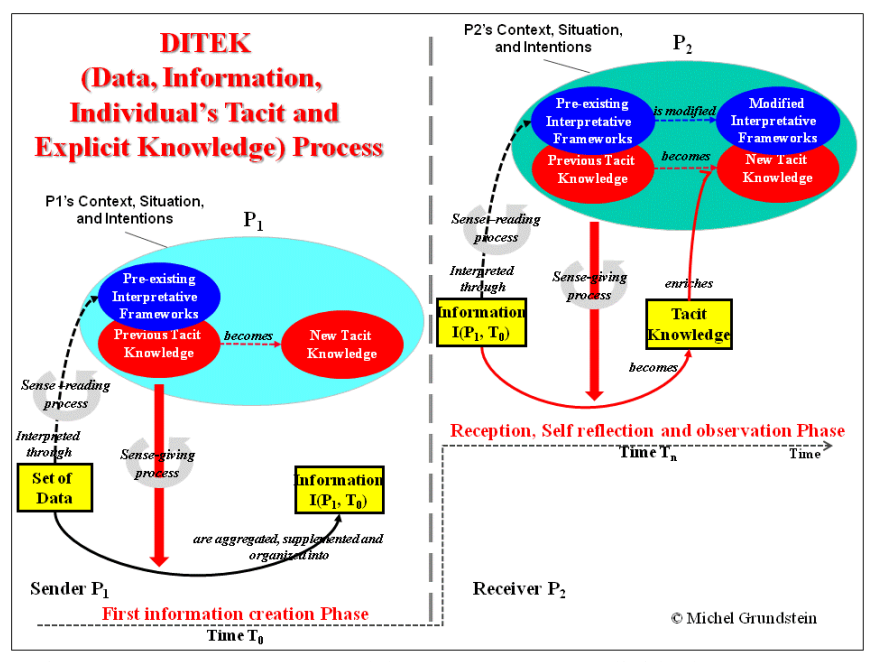

Figure 2. DITEK Process Model: From Data...to Individual's Tacit Knowledge 
In a first step, $\mathrm{P}_{1}$, in his context and situation, gathers a set of data outside him. Then, during a sense-reading process that depends of his preexisting interpretative frameworks activated depending of his context, his situation, and his intentions, he selects some of these data that take sense for him. In the same time, a sense-giving process using $\mathrm{P}_{1}$ 's previous tacit knowledge enables $\mathrm{P}_{1}$ to aggregate, and organize selected data he perceived, into information. It is this information that is passed on by the individuals, or by means of the DIS where it is stored, treated and transmitted as a stream of digital data. During this process, $\mathrm{P}_{1}$ 's pre-existing interpretative frameworks are not changing; previous tacit knowledge can be reorganized and modified into new tacit knowledge.

In a second step, in a reception, self-reflection and observation phase, this information is captured by $\mathrm{P}_{2}$. According to his own context and situation, $\mathrm{P}_{2}$, during a process of sense-reading, interprets this information filtering data through his pre-existing interpretative frameworks activated depending of his context, his situation, and his intentions. In the same time a sense-giving process that uses $\mathrm{P}_{2}$ 's previous knowledge operates, and engenders new tacit knowledge. That's the way that changes $\mathrm{P}_{2}$ 's preexisting framework and enriches $\mathrm{P}_{2}$ 's previous tacit knowledge enabling $\mathrm{P}_{2}$ to understand his situation, identify a problem, find a solution, decide, and act. The results of these processes are modified interpretative frameworks, and new tacit knowledge.

The process of transformation of data into knowledge is a process of construction of knowledge. Created knowledge, can be very different from one individual to another when the commensurability of their interpretative frameworks is small, whatever are the causes of it. There are large risks that the same information takes different senses for each of them, and consequently generates a construction of different tacit knowledge in the head of the decision process stakeholders. Unlike the information, knowledge is dynamic. Once constructed it cannot be considered as an object independent from the individual who built it, or the individual who appropriates it to make a decision and to act.

In a third step (Fig.3), when a dialogue is established with a receiver $\mathrm{P}_{3}$, during a tacit knowledge articulation phase, a sense-giving process enables $\mathrm{P}_{2}$ to articulate a part of his new tacit knowledge into explicit knowledge that is no more than information for $\mathrm{P}_{3}$.

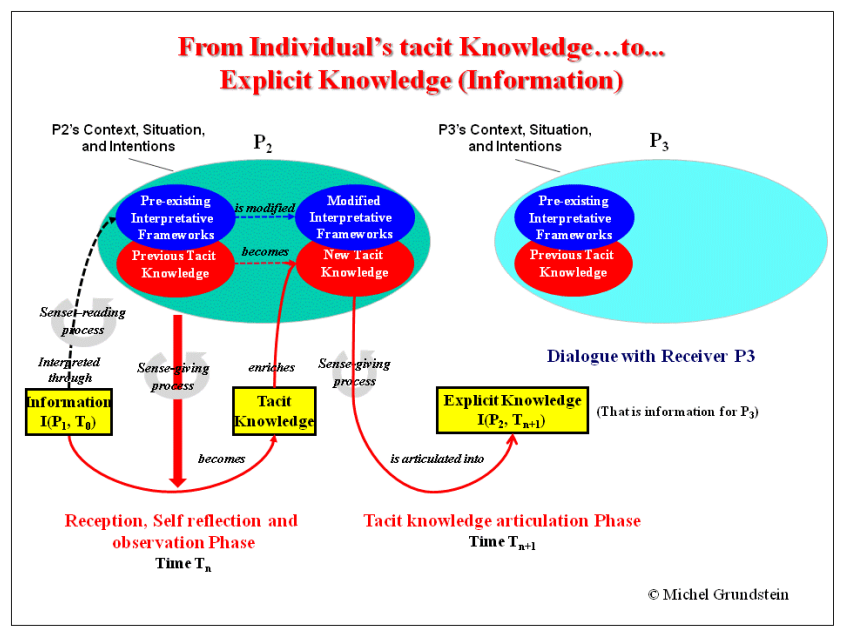

Figure 3. DITEK Process Model: From Individual's Tacit Knowledge...to Explicit Knowledge

As a result one can understand the importance to clearly distinguish static factual information, which allows describing the context and the situation that raise a problem, from the knowledge of the individual who processes this information to learn and get knowledge he needs to carry out his tasks.

Consequently, if "Technology provides the possibility of making information available across time and space" (Kautz and Kjaergaard 2008, p. 49 ) we always have to keep in mind, paraphrasing Kautz and Kjaergaard, "the role of individual in the knowledge sharing process, but we do also pay attention to how individual use technology to share knowledge (p. 43)." To answer this issue, distinguishing information from knowledge leads to conceive what we call Enterprise's Information and Knowledge Systems (EIKS).

\section{ENTERPRISE'S INFORMATION AND KNOWLEDGE SYSTEM (EIKS)}

\subsection{EIKS Description}

The enterprise's information and knowledge system (EIKS) consists mainly in a set of individuals and digital information systems. EIKS rests on a sociotechnical fabric, which consists of individuals in interaction among them, with machines, and with the very EIKS. It includes (Fig. 4):

- A Digital Information Systems (DIS), which are artificial systems, the artifacts designed from information and communication technologies (ICT)

- An information system constituted by individuals who, in a given context, are 
processors of data to which they give a sense under the shape of information. This information, depending of the case, is passed on, remembered, treated, and diffused by them or by the DIS.

- A knowledge system, consisting of tacit knowledge embodied by the individuals, and of explicit knowledge formalized and codified on any shape of supports (documents, video, photo, digitized or not). Under certain conditions, digitized knowledge is susceptible to be memorized, processed and spread with the DIS. In that case, knowledge is no more than information.

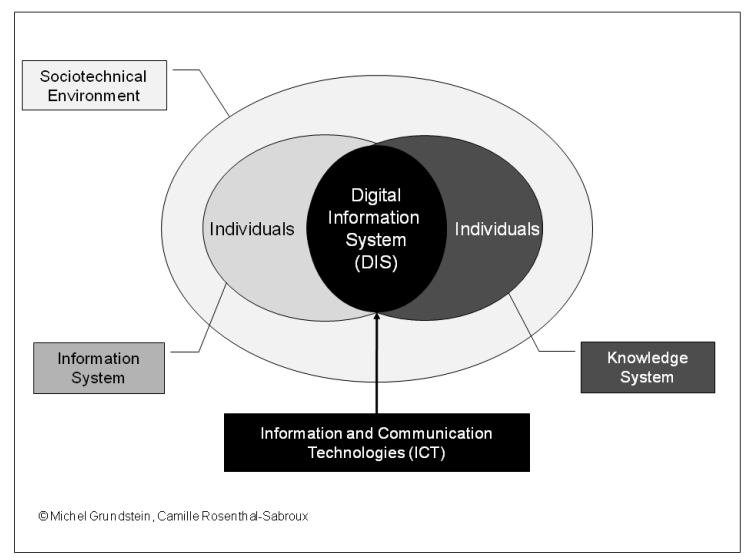

Figure 4. The Enterprise' s Information and Knowledge System (EIKS)

In EIKS, the information and knowledge portals have become essential for the knowledge workers who have to share with colleagues disseminated all around the world.

\subsection{Knowledge Workers as Users, and EIKS' Components}

Considering EIKS, portals must be seen as collaborative Information Systems, as mentioned by Chua and Brennan (2004) in their study on Collaborative Knowledge Management System (CKMS) defined as follows: "A Collaborative Knowledge Management System (CKMS) is an integrated systems tool that enables collaboration between its users and its components". They emphasize that "one of the most important components of CKMS is the knowledge workers, which are also the users of the system, and the workspaces they are associated with". Moreover, when analyzing ISO/IEC 9126 Quality Standard, Chua and Brennan pointed out: "Existing interpretations of ISO 9116 account for their role as users however not for their role as systems components."

We insist on the importance to integrate the individual as a component of the system. In fact, relying to our assumptions, we argue that knowledge resides primarily in the heads of individuals, and in the social interactions of these individuals. Knowledge is dependent of the individual's interpretative frameworks, and the context of his action. Consequently, as mental models and interpretative frameworks are directly forged by cultural factors, it induces to stress the role of cultural factors when social interactions and sharing information and knowledge are essential to enable efficiency in the global economy. Therefore, the project manager should consider the individual (knowledge worker and decision-maker) both at once as a user, and a component of the EIKS. Consequently, the conception of the digital Information System has to take into account the nature of the information that the individual, as a decision-maker, must be able to access.

Three natures of information must be distinguished: the Mainstream-Data, the Source-ofKnowledge-Data, and the Shared-Data (Grundstein and Rosenthal-Sabroux, 2003, pp. 980-981). Among the tools, the Information and Knowledge Portals supply a global access to the information, and can meet the needs of Knowledge Sharing. In that case, the functional software and the tools answering the aim of $\mathrm{KM}$ are integrated into the Digital Information System.

\section{GENERAL KM INITIATIVE ROADMAP}

A general KM initiative shows willingness, at the highest level of the enterprise, to encourage all the steps, and to implement all the means leading to capitalize on knowledge to pull strategic advantages of it. Many organizations established KM roadmaps aimed to find the way to develop KM initiative. For example, let's quote the Knowledge Management National Project undertook by the Office of the Deputy Prime Minister as part of the UK's Local Government Programme (Mangham and Kodlubanski, 2004). Afterwards, we refer to our own studies about General KM Initiative Development (Grundstein, 2005).

\subsection{General KM Initiative Development}

As roadmaps, general KM initiative development defines a vision and clarifies orientations and agenda 
linked with the enterprise's strategies. It declines under shape of projects identified formally which, beyond orientations and agenda, regroup all the previous existing initiatives. Every project is characterized by the specific context in which it is launched. So, the following description is a rough guide allowing the reader to conceive a general wellbalanced KM initiative, centred on the individuals, and taking into account a technological approach, and a managerial and sociological approach of KM.

There exist three main development phases: (i) The Strategic Orientation Phase which aim is to establish KM Initiative outline and agenda; (ii) Operational Management Phase which aim is to design and specify specific projects linked to capitalizing on knowledge problems; and (iii) Projects Deployment Phase which aim is to monitor and implement KM Systems.

For the purpose of this paper, we will focus on the first phase, the strategic orientation phase.

\subsection{Strategic Orientation Phase}

The strategic orientation phase of general KM initiative leads to establish KM initiative outline and agenda, taking into account priorities and available resources. Questions which must be considered focus notably on achieving alignment of the KM strategy on the Enterprise's strategy:

- How to articulate the general KM initiative with the Enterprise's strategic orientations?

- How to make the Enterprise's members, whatever are their hierarchical level, aware of KM interest for them, and the Enterprise?

- How to assess the Enterprise's KM maturity and its capacity to implement KM projects?

- How to define the KM initiative outline, and the agenda?

- What are predictable impacts?

- How to gather constructive conditions?

- What are the activities to develop and promote?

- What are the indicators to set up?

- How to establish relevant organizational structures, and to attribute roles to stakeholders?

- How to create and support organizational learning processes leading towards more exchange of information, and knowledge sharing?

The strategic orientation phase includes four steps: (i) Elaborating the Enterprise's KM Vision; (ii) Aligning KM Strategy on Enterprise's Strategies; (iii) Monitoring KM Maturity Study; and

(iv) Establishing KM Initiative Program.

Detailed descriptions are presented on Figure 5.

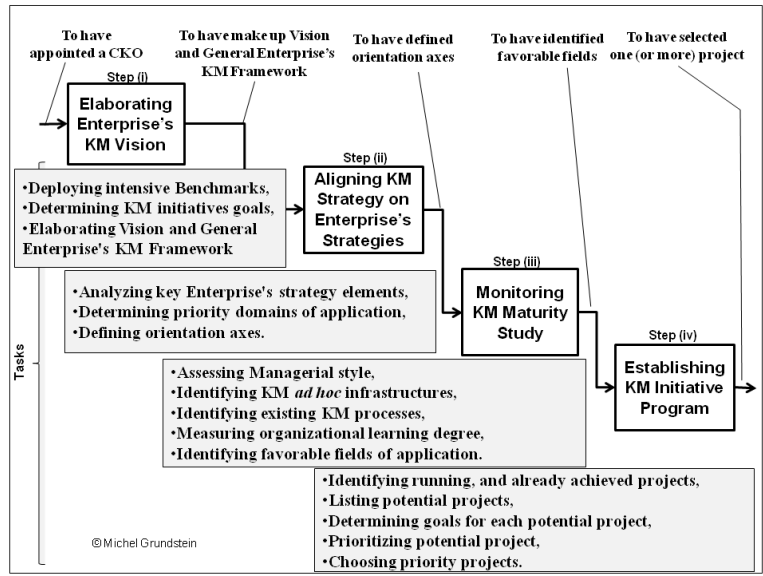

Figure 5. The Strategic Orientation Phase

\subsection{How to Avoid to Get KM Resources Unused}

The Strategic Orientation Phase is crucial and can avoid to get KM resources go unused as noticed by Stewart (Stewart, 2002) "One flaw in knowledge management is that it often neglects to ask what knowledge to manage and to what end (p.117)." We should add that KM is often oriented towards Information and Communication Technologies (ICT) that leads confusing notions of information and knowledge, and misunderstanding the goals: do we have to develop an Information System or do we have to implement a KM System?

Therefore, the Strategic Orientation Phase must help to build a general KM vision that makes a clear distinction between technology as a support to share individual's tacit knowledge, and technology as a means to collect, store, and distribute explicit and codified knowledge that is no more than information (see $\S 2.1$ ).

Beyond benchmarking studies, to deal with the Strategic Orientation Phase, Enterprises need a Meta model that is a pattern of reference (a template) in order: (i) to integrate KM Governance principles (Grundstein, 2007, pp. 247-248); (ii) to adapt it to their own situation; (iii) to monitor KM Maturity study (Grundstein, 2008, p. 424); and (iv) to envision integrating Information systems and KM systems in the same both digital and human system that we call EIKS .

\section{CONCLUSIONS}

Knowledge cannot be considered as an object such as data are in digital information systems. However, considering technological approach of KM, we 
highlighted the predominant positivist paradigm that underlies this approach, inducing to consider the knowledge as an object, and so to disregard the importance of individual's tacit knowledge used in action. Although the technological approach is greatly shared, without awareness, when elaborating KM initiative's strategy, we can confuse the notions of information and knowledge. Therefore, to avoid misunderstanding during the strategic orientation phase of a Knowledge Management initiative development, we pointed out that it was fundamental to clearly distinguish the notion of information from the notion of knowledge. We suggested an empirical model enabling to distinguish the notions of information and knowledge. Furthermore, we insisted on the importance to integrate the individual, both at the same time, as a user and a component of the system.

Distinguishing Information from Knowledge open our mind on a different view of information systems that leads to conceive what we call Enterprise's Information and Knowledge Systems (EIKS). These systems include individuals and are based on Digital Information System (DIS). This pragmatic vision needs thinking about the architecture of an Enterprise's Information and Knowledge System (EIKS), which must be a basis of discussion during the strategic orientation phase of general KM initiative development.

\section{ACKNOWLEDGEMENTS}

I am grateful to Camille Rosenthal Sabroux and Virginie Goasdoue whose continuous contribution and relevant questioning encouraged me to clarify and improve the model presented in this paper.

\section{REFERENCES}

Amin, A., Cohendet P., 2004. Architectures of Knowledge, firms, capabilities, and communities. New York US: Oxford University Press Inc.

CEN-1, 2004. Knowledge Management Framework. In European Guide to Good Practice in Knowledge Management (Part 1). Brussels: CEN, CWA 149241:2004 (E). Retrieved June 19, 2004, from $\mathrm{ftp} / / /$ cenftp1.cenorm.be/PUBLIC/CWAs/eEurope/KM/CWA14924-01-2004-Mar.pdf

Chua B.B., Brennan J., 2004. Enhancing Collaborative Knowledge Management Systems Design. In D. Remenyi (Ed.), 5th European Conference on Knowledge Management (pp.171-178). Reading, UK: Academic Conferences Limited, 2004.
Davenport T. H., Prusak L., 1998. Working Knowledge. Harvard Business School Press, Boston.

Grundstein M., Rosenthal-Sabroux C., 2003. Three Types of Data For Extended Company's Employees: A Knowledge Management Viewpoint. In M. KhosrowPour (Ed.), Information Technology and Organizations: Trends, Issues, Challenges and Solutions, 2003 IRMA Proceedings (pp. 979-983). Hershey, PA: Idea Group Publishing.

Grundstein M., 2005. Pilotage d'un projet Global de Knowledge Management (PGKM). Research Report \#12. Paris, France: MG Conseil (www.mgconseil.fr ).

Grundstein M., 2007. Knowledge Workers as an Integral Component in Global Information System Design. In Wai K. Law (Ed.), Information Resources Management: Global Challenges (Chapitre XI, pp. 236-261). Hershey PA: Idea Group Publishing, 2007.

Grundstein, M., 2008. Assessing the Enterprise's Knowledge Management Maturity Level. Int.J. Knowledge and Learning, Vol.4, No. 5, pp. 415-426.

IMKA, 1990. IMKA Technology Technical Summary, July 30, 1990. IMKA project was formed by Carnegie Group, Inc., Digital Equipment Corporation, Ford Motor Company, Texas Instruments Inc., and US West Advanced Technologies Inc.

Haeckel, S., H., 2000. Managing Knowledge in Adaptive Enterprises. In C. Despres and D. Chauvel (Eds), Knowledge Horizons (chap. 14, pp. 287-305). Woburn, MA: Butterworth-Heinemann.

Jennex, M. E., 2005. What is Knowledge Management? International Journal of Knowledge Management, Vol.1 No.4, pp. i-v. Hershey PA: Idea Group Publishing.

Kautz, K., Kjaergaard, A., 2008. Knowledge Sharing in Software Development. In P. A. Nielsen and K., Kautz (Eds), Software Processes \& Knowledge. Beyond Conventional Software Process Improvement (Chapter 4, pp.43-68). Aalborg, Denmark: Software Innovation Publisher, Aalborg University.

Kjaergaard, A., Kautz, K., Nielsen, P. A., 2008. Making sense of Project Management. In P. A. Nielsen and K., Kautz (Eds), Software Processes \& Knowledge. Beyond Conventional Software Process Improvement (Chapter 5, pp.71-87). Aalborg, Denmark: Software Innovation Publisher, Aalborg University.

KMIS 2009. International Conference on Knowledge Management and Information Sharing. Madeira, Portugal. Extracted, from http://www.ickm.ic3k.org/ April 2009

Laudon K C, Laudon J P., 2006. Management Information Systems; Managing the Digital Firm. Upper Saddle River, New Jersey: Pearson Education, Inc, (Ninth edition).

Regan, E.A., 2007. Knowledge Management: Evolving Concept and Practice. The International Journal of Knowledge, Culture and Change Management, Volume 6, Issue 9, pp.11-24). http://www.Management-Journal.com

Sena J.A., Shani A.B., 1999. Intellectual Capital and Knowledge Creation: Towards an Alternative 
Framework. In J. Liebowitz (Ed.), Knowledge Management Handbook (chapter 6, pp. 6.1-6.29). Boca Raton, Florida: CRC Press LLC.

Snowden, D., 2000. The Social Ecology of Knowledge Management. In C. Despres \& D. Chauvel (Eds) Knowledge Horizons (chap. 12, pp. 237-365). Woburn, MA: Butterworth-Heinemann.

Stewart, Th. A., 2002. The Wealth of Knowledge: Intellectual Capital and the 21tst century Organization. New York, USA: Currency Doubleday.

Takeuchi H., Nonaka, I., 2000. Theory of Organizational Knowledge Creation. In D. Morey, M. Maybury, B. Thuraisingham (Eds), Knowledge management, Classic and Contemporary Works (Chapter 6, pp. 139182). Cambridge, MA: The MIT Press.

Tsuchiya S., 1993. Improving Knowledge Creation Ability through Organizational Learning. ISMICK'93 Proceedings, International Symposium on the Management of Industrial and Corporate Knowledge, UTC, Compiègne, October 27-28, 1993.

Wiig, K., 2004. People-Focused Knowledge Management. How Effective Decision Making Leads to Corporate Success. Burlington, MA: Elsevier ButterworthHeinemann.

Wiig, K., 2008. Knowledge Management for the Competent Enterprise. Business Intelligence Vol. 8, No. 10. Cutter Consortium.

Mangham A., Kodlubanski, D., 2004. Charting the KM roadmap. InsideKnowledge Vol. 7 Issue 8). England: Ark Group Ltd. Extract May, 2009 from http://www.ikmagazine.com/xq/asp/sid.0/articleid.9F9 6C713-147A-473E-8A45-

DE623A7D26E6/eTitle.Charting_the_KM_roadmap/q x/display.htm 